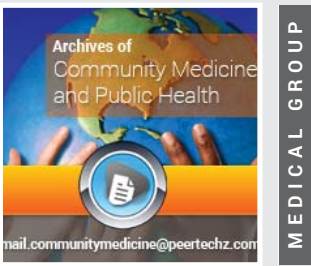

Lucélia Cunha Magalhães*, Silva DO, Araújo MJ, RN Lessa I, Almeida Filho $\mathrm{N}$, Aquino EML

Instituto de Saúde Coletiva-UFBa, Brazil

Received: 27 May, 2019

Accepted: 19 August, 2019

Published: 20 August, 2019

*Corresponding author: Lucélia Cunha Magalhães, Instituto de Saúde Coletiva-UFBa, Brazil,

E-mail: Iuceliamagalhaes@terra.com.br

https://www.peertechz.com

Check for updates

\section{Research Article \\ Sedentarism and Metabolic Syndrome: Broadening the measurement of sedentarism}

\begin{abstract}
The metabolic syndrome (MS) is a combination of cardiovascular risk factors, including visceral obesity, low HDL cholesterol level, increased triglycerides, hyperglycemia and high blood pressure. This sequence of risk factors contributes towards the development of atherosclerotic cardiovascular disease (ACVD) and diabetes mellitus. Sedentarism is not widely studied. This habit is a determinant factor for chronic or acute diseases. This study tests the hypothesis of the association between overall sedentarism, including professional work, travel and leisure and the MS, in adult men and women in Salvador, Bahia. A population based cross-sectional study of both genders, ages $\geq 20$ years. MS is defined by the criteria of the International Diabetes Foundation, characterized as the MS when considering the presence of abdominal obesity (waist $\geq 84 \mathrm{~cm}$ for women and $\geq 88 \mathrm{~cm}$ for men) plus two of the following criteria: arterial hypertension $(\geq 130 / 85 \mathrm{mmHg})$ hyperglycemia $(\geq 100 \mathrm{mg} / \mathrm{dl})$ hypertriglyceridemia $(\geq 150 \mathrm{mg} / \mathrm{dl}$ ). Hypoalphalipoproteinemia (hdl-cholesterol below $40 \mathrm{mg} / \mathrm{dl}$ for women and below 50 for men). Sedentarism is defined by means of the four criteria of physical inactivity described below. Athletes were excluded. Inactivity in the professional work: lack of physical activity in the professional work or the presence of light physical activity such as: working mostly seated or less than $25 \%$ of the time standing or moving around. Inactivity in household work: lack of household work or light work, such as small repairs, light cleaning or preparation of food. Physical inactivity during travel to work: traveling by car or bus, walking less than 30 minutes as well as performing most of the outside activities by car or walking. Physical inactivity during leisure: leisure does not include physical activities. The final sample totaled 1,333 individuals. In logistic regression, the adjusted prevalence ratio (PR) of overall sedentarism and the MS for women was of 1.31 (CI95\% 0.86-1.91). For men the adjusted prevalence ratio was of 1.68 ( $\mathrm{Cl} 95 \%$ $1.05-2.53)$, statistically significant. This paper reveals, in men, that overall sedentarism is associated to the MS. There was no statistically significant association between sedentarism exclusively in leisure and the MS. Marital status was a confounding factor and raises the issue of this variable not being widely studied as a cardiovascular risk factor.
\end{abstract}

\section{Introduction}

Since the eighties, with the publication of the first studies by Framingham [1] and Tromso [1], it was demonstrated that physical inactivity is associated to the risk of cardiovascular morbi-mortality. Subsequent studies confirmed these findings and added the knowledge that physical inactivity is also associated to general mortality $[3,4]$, as well as to the development of arterial hypertension [5], diabetes [6] and obesity [7]. In further analysis to these initial cohorts, it was determined that the increased mortality in inactive individuals was due to excess weight, with this association having been confirmed over the years. More recent studies, such as Lee \& col. [8], evidenced that the relationship between health and physical activities could be better represented by a "J" curve, in other words, both sedentarism and strenuous physical effort are associated to higher general and cardiovascular morbi-mortality. Stevens \& col. [9], and Wei \& col. [10], demonstrated that the association between sedentarism and cardiovascular risk was independent of the increase in corporal fat, independently of the indicator used - weight, body mass index (BMI), waist/hip index ratio or abdominal waist. This was confirmed for men and women. In accordance with the line of investigation, the cardiorespiratory capacity of the individuals was more important than corporal fat, and more associated to health than the quantity of corporal fat. As opposed to this theory, a recent article in 2006, Diaz \& col. [11] demonstrated that individuals not overweight or obese have improved cardiovascular risk profiles when compared to those with overweight or obesity with good physical capability, assessed by means of a stress test. 
Sedentarism can be measured in various manners, the most frequent manner being an assessment only in relation to leisure activities [8-10]; and more rarely in professional work [12]. Nevertheless, the extension of the assessment of sedentarism incorporated to the daily routine, such as household activities and travel time to perform routine activities, begins to be demanded when further studying the relationship between sedentarism and health.

Accordingly, around a decade ago, studies began to emerge associating a higher cardiovascular risk not only in relation to sedentarism in leisure and work, but also in relation to other activities of the individual, such as the amount of time spent in front of the "screen" (TV, computer, games, etc.). This broader form of assessing physical inactivity has been described as "sedentary behavior", and, presently, is assessed as an important indicator of cardiovascular risk. For Dietz [13], sedentarism is defined as a state in which there is a minimum amount of corporal movement. According to the mentioned author, "minimum movement" is different than physical activity and represents a behavior that is always associated to adverse effects to health, today defining physical activity of light to moderate intensity being associated to protection, and physical activity of high intensity being associated to risks.

The recent trend of investigating classic cardiovascular risk factors, as an aggregate, has contributed towards a better understanding of the determination of morbid events in its the various phases of development. Since 2004, the metabolic syndrome was defined as a combination of interrelated cardiovascular risk factors, including visceral obesity, low HDL cholesterol levels, increased triglycerides, glycaemia and blood pressure [14]. Presently, the MS is an important mediator in the increased risk of cardiovascular atherothrombosis (CVAT) and diabetes mellitus type 2 [15].

Studies on physical inactivity and the MS are still scarce in literature, despite the association of both phenomena being plausible. The majority of the existing studies is of clinical design and physical inactivity assessed by one of its consequences, low physical performance, measured by means of a stress test [16-21]: Others are intervention studies [22,23], most of which [17,19-21] assessed physical activity during leisure and demonstrated that good physical conditions in this sphere of life is inversely associated to MS or to its components. However, the survey by Whaley \& col. [16], the only one that did not confirm this association, was published in 1998, when there was still a profound uncertainty as to the criteria of the MS, which only began to be well established as of January 2004 [15]. Recently, also in a cohort study, Laaksonen \& col. [21] Demonstrated that a short period of physical activities during leisure, with low cardiorespiratory capacity, was a predictive factor for the development of the MS.

Two cross-sectional studies were identified that assessed the role of "sedentary behavior" in a more comprehensive manner, including physical inactivity during leisure and in household activities. The study of Ford \& col. [24] indicated that individuals that do not engage in any kind of physical activity, of moderate and vigorous intensity, during their leisure time, had double the case of developing MS.
Additionally, individuals who watched TV, or other activities in front of screens, outside their working hours, for over 4 hours per day, also had a risk for developing the MS. In the study of Bertrais et col. [25], the frequency of the components of the MS increased with the time spent in front of a computer screen, videos or TV, when compared to individuals engaged in any daily physical activity, either in their leisure time or at work.

National studies on physical activities or sedentarism, associated to the MS were not identified. Some studies are descriptive and point out to the prevalence of physical inactivity during leisure periods. A study on adults, in Pelotas, Rio Grande do Sul, demonstrated that $41 \%$ of individuals presented this type of sedentarism [26]. In another descriptive study in a representative sample of the city of São Paulo, $87 \%$ of the individuals were sedentary during their leisure [27]. A study on some of the constituents of the MS, such as hypertension, diabetes mellitus, overweight and obesity associated to physical inactivity were identified, demonstrating a high prevalence in all age groups [28]. Pitanga \& Lessa [29] indicate that $60.4 \%$ of men and $82.7 \%$ of women were sedentary in their leisure periods, which was directly associated to low schooling levels and marital status, mostly prevailing among the married women.

Population based studies, assessing sedentarism under different aspects, such as in household activities, professional work, displacement during routine activities and in leisure periods and the

MS were not found. Thus, the present investigation aimed to fulfill this knowledge gap, studying sedentarism in its different demonstrations, and associating it to the MS.

\section{Methodology}

This study is part of the Cardiovascular Disease Monitoring Project ("Monite"), developed by the Public Health Institute ("Instituto de Saúde Coletiva"), of Universidade Federal da Bahia, as support to Cenepi - Centro Nacional de Epidemiologia/ Ministério da Saúde (National Center for Epidemiology/Ministry of Health). It is characterized for being a population based cross-sectional study performed between 1999 and 2000, in a sample of adults, of both genders, of ages equal to or above 20 years, residents of private permanent homes in the city of Salvador, Bahia. Pregnant women were excluded.

The area of coverage was defined based on a sample of a study described previously [30], on health conditions, carried out in Salvador. A cluster sample was selected in two stages:

- First stage: simple random sample of residences without replacement based on the register of the mentioned study [30].

- Second stage: after the register of all the adults, one man and one woman, of ages equal to or over 20 years, were chosen in each house, by draw.

The size of the theoretic sample for the domiciles was 
estimated according to expected prevalence of arterial hypertension of $15 \%$, arterial coronary disease of $5 \%$, obesity of $30 \%$ and diabetes of $7 \%$. A variation coefficient of $5 \%$ was used, for a confidence interval of $95 \%$. Considering the existence of partially performed interviews, and interview not performed, at the residences, the weights of the respective homes were calculated. Nevertheless, this was not considered in the final statistical analysis once some units presented negative weights.

The data production was by means of face-to-face interviews with the application of a structured instrument and of measurement procedures of biological measures. The questionnaire encompassed sociodemographic information, physical activities, nourishment, tobacco, consumption of alcoholic beverages and personal health. Blood pressure measurements were taken, using OMRON HEM 705 CP digital equipment and "standard and big adult" cuffs, previously validated [31]. Measurements were performed on the left arm of the seated individual, divided into two blocks of three (total of six measurements): the $1^{\text {st }}$ block, after at least 5 minutes of rest, and the $2^{\text {nd }}$ block, with at least 20 minutes of interval from the $1^{\text {st }}$ block, with the individual remaining seated during this interval. The material for blood exams was collected in a chosen health center, using standard techniques [32] and adopting the following ones: glycaemia, Labtest technique; HDL cholesterol, Labtest technique; triglycerides, modified Soloni technique.

Anthropometric measurements were performed, with the individual barefoot and using light clothing. A standard inelastic measuring tape, of synthetic material, was used to measure waist circumference, defined as midpoint between the last rib and the iliac crest.

Interviews were carried out by interviewers with minimum schooling levels of secondary school graduates and prior experience in field research, selected and trained for this purpose.

For quality control, a sub-sample of $10 \%$ of the interviewed parties was selected, whereby a reviewer repeats the questionnaire and the measurements.

For setting up the databank, the EPIINFO, version $6.04 \mathrm{~b}$, software was used and for analysis the STATA version 8.

In the analysis, the dependent variable was the Metabolic Syndrome, defined based on the criteria of the International Diabetes Foundation [33]. The Metabolic Syndrome was considered when, in the presence of abdominal obesity - for men with waists measuring $88 \mathrm{~cm}$ or more and for women with $84 \mathrm{~cm}$ or more [34]. Over two of the following criteria were fulfilled: arterial hypertension; hyperglycemia; hypertriglyceridemia; hypoalphalipoproteinemia. Hypertension was defined by the average of the six measurements of the systolic arterial pressure (SAP) greater or equal to $130 \mathrm{mmHg}$, or diastolic arterial pressure (DAP) equal or greater than 85 mmHg; hyperglycemia was defined by the 9 hour fasting glycaemia, equal or greater than $100 \mathrm{mg} / \mathrm{dl}$; triglycerides serum hypertriglyceridemia obtained after a 12 hour fast greater or equal to $150 \mathrm{mg} / \mathrm{dl}$ and hypoalphalipoproteinemia from low plasma HDL-cholesterol, for men below $40 \mathrm{mg} / \mathrm{dl}$ and for women below $50 \mathrm{mg} / \mathrm{dl}$. Amounts below amounts of reference were included for individuals under treatment for regular hypertension, hyperglycemia and dyslipidemia.

The main independent variable is sedentarism defined as of four criteria of physical inactivity:

- In the professional work: work performed almost exclusively seated or standing for less than $25 \%$ of the total time or in short displacements.

- In household work: not performing any work or only small repairs or light cleaning work and preparation of meals.

- Traveling to work: going and returning by car or bus and walking less than 30 minutes. Performing outside tasks mostly by car or bus.

- Leisure: not including daily physical activities of moderate or vigorous intensity. Only including light non-routine walks.

Athletes were excluded (reference of intense physical activity over the last 12 months). This decision was supported by the most recent understanding that athletes are part of a very heterogeneous group in relation to cardiovascular risks $[4,5,35]$.

Sedentarism exclusively in leisure was additionally analyzed separately, with the purpose of comparison with literature. In this case athletes were included.

The co-variables analyzed were: age, self-referred race/ color (white, brown, black and others such as East Asians and indigenous), schooling, recent migration, marital status, tobacco, menopause and alcohol consumption.

Data analysis involved the initial description of the variables of interest, with the purpose of characterizing the population of the study. Differences between proportions were tested in relation to statistical significance, using Pearson $\chi^{2}$ at the level of $5 \%$. Prevalence was calculated as measure of frequency and prevalence ratio (PR) as a measure of association.

In the stratified analysis, the Mantel-Haenszel method was used to estimate the prevalence ratio, confidence intervals and verification of the difference between the strata (considering a p-value $\leq 0.05$ ). The identification of the effect modification was preceded by means of the observation of the behavior of the stratum-specific measurements, in relation to the confidence intervals of the opposing strata. Each PR was compared with the confidence interval of the following category, and when this PR was not contained in the confidence interval, the variable was considered as potential effect modifier. For the identification of probable confounders, the parameter used was the difference of approximately $10 \%$ for comparison of the gross association measure to the adjusted association measure, using the Mantel-Haenszel method. 
Unconditional logistic regression was used for obtaining association measure estimates, based on the maximum likelihood, with the purpose of confirming the hypothesis of the study. The backward strategy was used for the selection of variables, having included in the study all the variables in which the univariate tests obtained a p-value $\leq 0.25 \%$. For the criteria for permanence, in the final model, all the variables presenting statistical significance levels of $\leq 0.10$ were included. To verify the existence of effect modification, the likelihood ratio test was used, in the assessment of the deviation differences, comparing the complete model (with product terms) with the reduced model (without product terms) for alpha $\leq 0.05$. The confounding variables considered were those that when removed from the complete model produced a statistically significant difference in the isolated measurement of the leading association, considering confidence intervals of alpha $\leq 0.10$. Such procedures permitted the construction of a final model, based on the measures of the leading association, controlled by effect modifying variables, and adjusted by the confounding variables $[36,37]$.

The study complied with the requirements of the National Research Ethics Committee (Conepe), including the right of refusal in any phase of the study. Confidentiality and privacy of information was guaranteed, as well as access to the results of the exams and priority in the attendance to individuals with complaints or with abnormal laboratory exams, at the primary healthcare units of reference for the project. This study was approved by the Ethics Committee of the Bahia Regional Medical Council ("Comitê de Ética do Conselho Regional de Medicina do Estado da Bahia”).

\section{Results}

The effective sample was composed of 1,503 units, with $90.2 \%$ of the homed having been visited. Out of the 2,442 eligible individuals, $94.4 \% 2343$ interviewed; from these, 1,333 $(58.0 \%)$ took part in all of the phases, including exams and measurements, comprising the population of this study.

The individuals not included, compared to those examined, were more frequently young men, white, not working at the time of the interview, with no knowledge of any prior diagnosis of arterial hypertension or hyperglycemia.

Sedentarism in leisure and at work predominated among women, being twice as frequent as men. Sedentarism during travel was also more frequent in women, although the differences were not so significant. Nevertheless, when analyzing sedentarism in the domestic environment, the standard is inverted, being 2.5 times more frequent among men. In the combination of sedentarism in the different spheres the result was of a higher incidence among women, with $62.7 \%$ vs. $37.3 \%$ for men. ( $p=0.000$ ) (Graph 1 ).

When grouping active and inactive (sedentary) individuals, in relation to sociodemographic characteristics, statistically significant associations are observed among women; for sedentary women, older, in the menopause and with higher schooling levels ( $p \leq 0.05)$. However, among the men, there were no statistically significant associations (Table 1 ).
The association between sedentarism and MS was determined. The gross prevalence ratio was of 1.64 (CI 95\% 1.01-2.64) for men and 1.52 (CI95\% 1.02-2.27) for women.

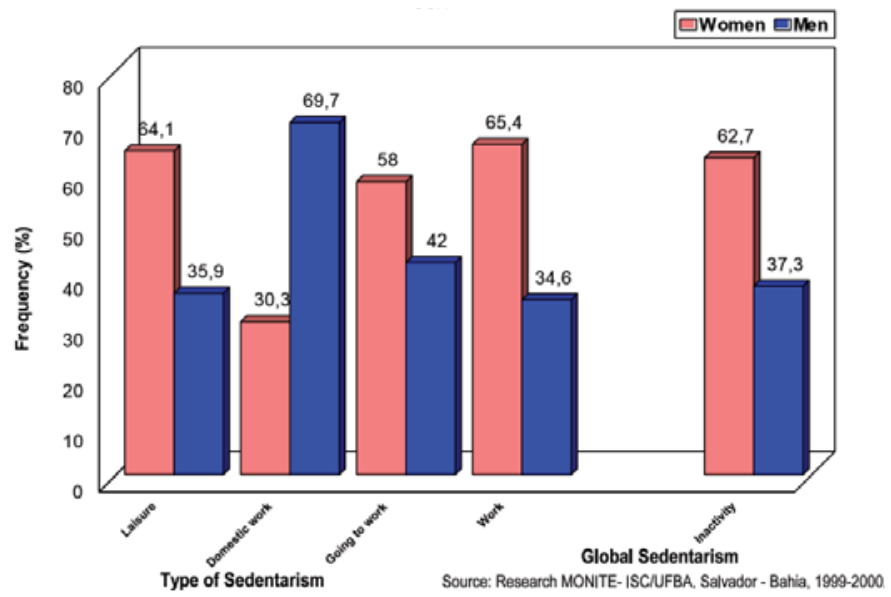

Graphics 1: Prevalence of diferentes types of sedentarism and global sendentarism by sex.

Table 1: Sociodemographic characteristics of the population of the study in relation to overall sedentarism in men and women. Salvador, BA, 1999-2000.

\begin{tabular}{|c|c|c|c|c|}
\hline \multirow{3}{*}{ Co-variables } & \multicolumn{2}{|c|}{ Women } & \multirow{2}{*}{\multicolumn{2}{|c|}{$\begin{array}{c}\text { Men } \\
\text { Active Inactive } \\
(n=112)(n=302)\end{array}$}} \\
\hline & \multicolumn{2}{|c|}{$\begin{array}{c}\text { Active Inactive } \\
(n=172)(n=506)\end{array}$} & & \\
\hline & (\%) & $(\%)$ & (\%) & (\%) \\
\hline Age & ${ }^{*} \mathrm{p}=0,000$ & & ${ }^{*} \mathrm{p}=0,069$ & \\
\hline $20-49$ & 86.1 & 68.4 & 78.6 & 69.5 \\
\hline 50 and over & 13.9 & 31.6 & 21.4 & 30.5 \\
\hline Race/Color & ${ }^{*} p=0.296$ & & ${ }^{*} \mathrm{p}=0.243$ & \\
\hline White & 9.3 & 13.8 & 10.7 & 13.2 \\
\hline Brown & 68.0 & 65.4 & 72.3 & 63.6 \\
\hline Black & 22.7 & 20.7 & 17.0 & 23.2 \\
\hline Schooling & ${ }^{*} p=0.015$ & & ${ }^{*} \mathrm{p}=0.504$ & \\
\hline Elementary (incomplete) & 26.7 & 21.2 & 16.1 & 21.2 \\
\hline Elementary (complete) & 21.5 & 14.8 & 19.6 & 17.9 \\
\hline Secondary complete/higher & 51.7 & 64.0 & 64.3 & 60.9 \\
\hline Smoker & ${ }^{*} p=0.151$ & & ${ }^{*} \mathrm{p}=0.932$ & \\
\hline Yes & 13.9 & 81.2 & 30.4 & 30.8 \\
\hline No & 86.1 & 18.8 & 69.6 & 69.2 \\
\hline Recent Migration & ${ }^{*} \mathrm{p}=0.884$ & & ${ }^{*} p=0.109$ & \\
\hline Yes $(<10$ years $)$ & 8.1 & 8.5 & 15.2 & 9.6 \\
\hline No & 91.9 & 91.5 & 84.8 & 90.4 \\
\hline Menopause & ${ }^{*} \mathrm{p}=0.002$ & & & \\
\hline Yes & 22.7 & 35.5 & $\cdots$ & $\ldots$ \\
\hline No & 77.3 & 64.5 & $\ldots$ & $\ldots$ \\
\hline Marital status & ${ }^{*} p=0.789$ & & ${ }^{*} \mathrm{p}=0.357$ & \\
\hline Single & 19.8 & 20.9 & 16.1 & 21.9 \\
\hline Married & 64.5 & 61.7 & 81.2 & 74.5 \\
\hline Widow(er)/Separated/Divorced & 15.7 & 17.4 & 2.7 & 3.6 \\
\hline Alcohol consumption & ${ }^{*} p=0.076$ & & ${ }^{*} p=0.953$ & \\
\hline Light and moderate & 48.3 & 40.5 & 58.9 & 58.6 \\
\hline Absent and excessive & 51.7 & 59.5 & 41.1 & 41.4 \\
\hline
\end{tabular}


In relation to the constituent parts, there was no statistically significant association between men and women, only blood pressure was significantly associated, with a PR of 1.47 (CI $95 \%$ 1.07-2.01). (Graphs 2,3).

In logistic regression, the adjusted prevalence ratio between sedentarism and MS was, for women, of 1.31 (CI 95\% 0.86-1.91). However, for men the adjusted prevalence for sedentarism and MS was of 1.68 (CI 95\%1.05-2.53). We draw attention to both genders, where the eldest, married and the divorced/separated/ widow(er)s; these associations were statistically significant, making these variables as confounders.

In adjusted logistic regression, assessing sedentarism exclusively during leisure, a PR of 1.01 for men (CI95\% 0.641.47) and for women a PR of 1.03 (CI95\% 0.68-1.51) was evidenced, with non-significant statistical associations (data not presented) (Table 2).

\section{Discussion}

Some aspects should be highlighted in this investigation. No other article was identified measuring self-referred sedentarism, considering its various dimensions, as was perfumed herein. Most of the studies either assess physical

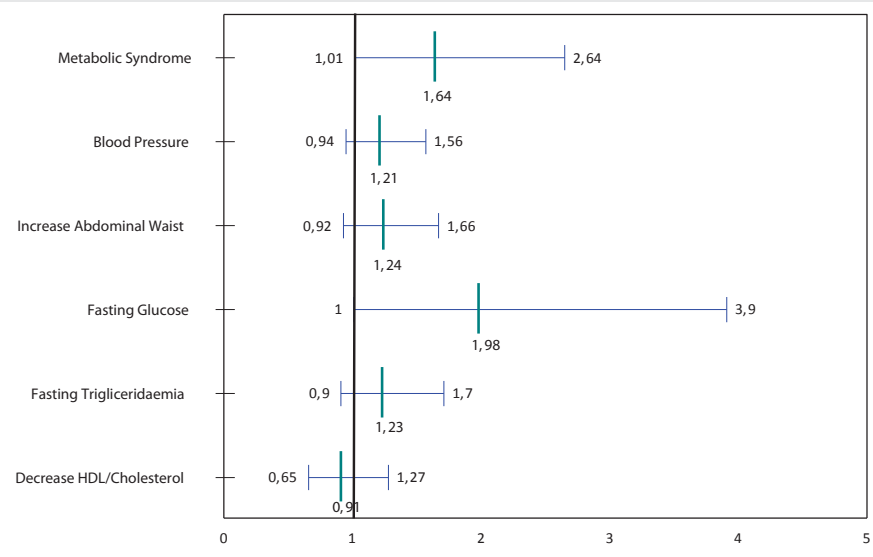

Source: Research MONITE - ISC/UFBA. Salvador - Bahia, 1999-2000.

Graphics 2: Prevalence Ratio of Metabolic Syndrome and their components (men) by sedentarism.

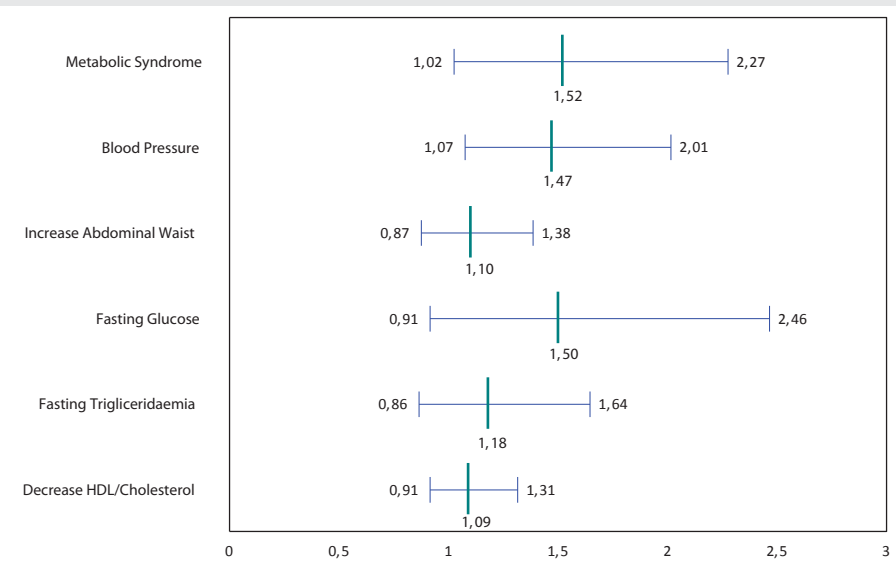

Source: Research MONITE- ISC/UFBA. Salvador - Bahia, 1999-2000. activity during leisure [17-21, 28-31], or add physical activities in the professional work $[12,24,25]$. The incorporation of sedentarism in household activities and in the travel to routine activities is necessary due to the social characteristics of this population. This sample was composed of around $80 \%$ of individuals belonging to the working class or to the poor [38], with the need to consider other forms of sedentarism, once these individuals may be very active in the household work and in the travel to their daily activities, and sedentary in their leisure activities. The analysis of sedentarism exclusively during leisure, or even including professional work, may be applied in populations of the first world, as can be verified in the quoted international publications. Populations of regions such as Scandinavia or North America are very different to the populations studied in this investigation, in relation to physical exertions. Despite those individuals having a lot of activities, they perform these activities in a frequently automatized manner, with the presence of equipment in their daily activities. Additionally, the populations of those studies have different living conditions than those of this study, where access to public or private transportation requires less physical effort, with lower caloric output. Accordingly, in this investigation, when measuring physical inactivity exclusively during leisure, it was not possible to obtain the association with MS found among men, which was observed when broadening the definition of sedentarism. In this investigation, measuring physical activities instead of sedentarism it was observed, only in relation to leisure, that $37 \%$ of men were active, against $16 \%$ of women. Different to the overall assessment of sedentarism, in the present investigation, where $62.7 \%$ of the men were active and only $37.3 \%$ of the women (data not presented).

In the final adjusted model, the statistical significance of the association between overall sedentarism and MS was maintained for men. Another four studies [21,39-41], assessing exclusively men, although only for sedentarism during leisure, demonstrated that physical inactivity was associated to MS or to its components.

In women, there was no significant association between overall sedentarism and MS. Some aspects should be observed in relation to similar studies. Out of the studies in which women were included in the analysis $[17,18,20,22]$, they presented good to excellent cardiorespiratory capacity, obtained in their free time and assessed using the stress tests in physical fitness clinics. These studies demonstrated inverse relation between MS and cardiovascular capacity. This population cannot be compared with the present investigation, due to the differences between the women in these studies. A specialist on sedentarism, researcher Wareham [42], mentions that this means of measuring physical activity cannot be applied or compared with populations of underdeveloped countries or countries under development.

One of the proposed possibilities for the null association, found in this study among women, may be the need for valuing more vigorous physical activities for protection against MS in women [43], in their leisure time or in other daily activities. It is possible that there is a need not only for them to be active, but to develop good cardiovascular capacity in order to have 
Table 2: Stratified analysis and logistic regression for association between overall sedentarism (active and inactive) and the metabolic syndrome.

\begin{tabular}{|c|c|c|c|c|c|c|c|c|c|}
\hline Variables & & & & Women & & & & Men & \\
\hline & $\mathrm{n}$ & Pre & $(\%)$ & PR (Cl 95\%) & PRAdjusted (Cl 95\%) n & & Prev. (\%) & PR (Cl 95\%) & PRAdjuisted (CI 95\%) \\
\hline Overall sedentarism & & & & & & & & & \\
\hline Active & 172 & & 14.5 & 1.00 & 1.00 & 112 & 15.2 & 1.00 & 1,00 \\
\hline $\begin{array}{c}\text { Inactive } \\
\text { Age (years) }\end{array}$ & 506 & & 22.1 & $1.52(1.02-2.27)$ & $1.31(0.86-1.91)^{\star}$ & 302 & 24.8 & $1.64(1.01-2.64)$ & $1.68(1.05-2.53)^{\star}$ \\
\hline $20-49$ & 494 & & 14.4 & $1.07(0.66-1.73)$ & 1.00 & 298 & 21.0 & $1.68(0.91-3.09)$ & 1.00 \\
\hline 50 and over & 184 & & 38.8 & $1.86(0.83-4.15)$ & $2.10(1.53-2.77)$ & 116 & 33.7 & $1.35(0.64-2.85)$ & $1.63(1.08-2.34)$ \\
\hline Adjusted Race/Color & & & & $1.89)^{1.26(0.83-}$ & & & & $1.55(0.96-2.50)$ & \\
\hline White & 86 & & 18.6 & $1.48(0.37-5.94)$ & & 52 & 27.5 & $0.83(0.32-2.12)$ & \\
\hline Brown and Black & 592 & & 22.7 & $1.54(1.02-2.33)$ & & 362 & 24.43 & $1.88(1.08-3.26)$ & \\
\hline Adjusted Schooling & & & & $1.53(1.03-2.29)$ & & & & $1.62(1.00-2.61)$ & \\
\hline Secondary complete/Higher & 153 & & 14.0 & $1.29(0.50-3.34)$ & & 82 & 26.6 & $1.60(0.53-4.84)$ & \\
\hline Elementary complete & 112 & & 10.7 & $1.32(0.37-4.67)$ & & 76 & 24.1 & $2.65(0.65-10.78)$ & \\
\hline Elementary incomplete & 413 & & 27.5 & $1.44(0.91-2.28)$ & & 256 & 24.5 & $1.47(0.82-2.61)$ & \\
\hline Adjusted Smoker & & & & $1.40(0.94-2.07)$ & & & & $1.63(1.00-2.63)$ & \\
\hline No & 559 & & 20.7 & $1.33(0.87-2.03)$ & & 287 & 25.8 & $1.83(1.01-3.32)$ & \\
\hline Yes & 95 & & 28.4 & $3.41(0.87-13.35)$ & & 127 & 22.6 & $1.28(0.56-2.90)$ & \\
\hline $\begin{array}{c}\text { Adjusted } \\
\text { Recent migration }\end{array}$ & & & & $1.51(1.01-2.26)$ & & & & $1.64(1.01-2.64)$ & \\
\hline No & 621 & & 23.1 & $1.59(1.05-2.40)$ & & 368 & 25.3 & $1.72(1.01-2.90)$ & \\
\hline Yes $(<10$ years $)$ & 57 & & 11.6 & $0.81(0.18-3.74)$ & & 46 & 20.7 & $1.17(0.34-4.09)$ & \\
\hline $\begin{array}{c}\text { Adjusted } \\
\text { Marital status }\end{array}$ & & & & $1.53(1.02-2.27)$ & & & & $1.63(1.00-2.64)$ & \\
\hline Single & 140 & & 14.2 & $\ldots$ & 1.00 & 84 & 9.1 & $1.64(0.21-12.73)$ & 1.00 \\
\hline Married & 423 & & 18.6 & $1.09(0.68-1.74)$ & $1.62(1.02-2.40)$ & 316 & 30.7 & $1.74(1.07-2.84)$ & $2.54(1.47-3.72)$ \\
\hline Divorced/Separated/Widow(er) & 115 & & 44.3 & $1.99(0.95-4.19)$ & $2.48(1.61-3.42)$ & 14 & 0.0 & $\ldots$ & $\ldots$ \\
\hline Adjusted Menopause & & & & $1.51(1.01-2.23)$ & & & & $1.74(1.08-2.79)$ & \\
\hline No & 458 & & 13.8 & $1.08(0.64-1.82)$ & & & & & \\
\hline Yes & 218 & & 36.9 & $1.80(0.94-3.43)$ & & & & & \\
\hline $\begin{array}{c}\text { Adjusted } \\
\text { Alcohol consumption }\end{array}$ & & & & $1.34(0.89-1.99)$ & & & & & \\
\hline Light and moderate & 288 & 17.6 & & $1.62(0.82-3.21)$ & & 243 & 22.6 & $1.50(0.79-2.81)$ & \\
\hline Absent and excessive & 390 & 25.2 & & $1.41(0.86-2.28)$ & & 171 & 28.0 & $1.84(0.88-3.85)$ & \\
\hline Adjusted & & & & $1.48(0.99-2.20)$ & & & & $1.64(1.01-2.64)$ & \\
\hline
\end{tabular}

*Adjusted for age and marital status.

this protection. Despite being active in their daily activities, only $1.2 \%$ of them were athletes and only $9.0 \%$ performed heavy professional work, against approximately $32 \%$ of men (data not presented).

Another two studies analyzed sedentary behavior [24,25], which included, apart from physical activities during leisure and professional work, they also measure the time spent on sedentary activities, such as watching TV, video games and on computers. From these variables, the authors created a composite indicator for the definition of what they call "sedentary behavior", associated to MS or to its components.
In the present investigation, eminently sedentary behaviors were not contemplated, and this may have decreased the power of this study to reveal the association among women, once this sedentary behavior is more frequent among women [25].

In relation to the measurement of physical activity during leisure and in the professional work, Liedfelt \& col. [12] demonstrated that middle-aged Swedish women and with lowschooling had association to the components of SM, due to the high physical activity of the professional work of these women with low schooling and almost no leisure activities. It should be emphasized that in that study, the definition of MS and 
the chosen cut-off points were different to the international standards. For example, to define high blood pressure, the study defined the cut-off point of $160 / 95 \mathrm{mmHg}$. This criterion, for sure, highly increased the specificity of the mentioned study, possibly explaining the statistically significant association found between the women. Furthermore, Liedfelt \& col. disclosed schooling as the confounding effect, whereby $75.4 \%$ of the women in the study had completed secondary school or were university graduates. In comparison to the present paper, only $22.6 \%$ had the same schooling level. This difference in schooling levels may have weakened the discriminatory power of our sample, in this aspect.

However, in the gross prevalence ratio, blood pressure, one of the constituent elements of MS, demonstrated a significant association, which leads us to presume that hypertension is more strongly associated to sedentarism in women than other components of MS. This is reinforced by Thompson \& col. [5], in the analysis of risk factors for the prevention of atherosclerotic diseases, where blood pressure and diabetes mellitus were attributed higher risks.

This study has limitations, the ideal assessment of the analysis of sedentarism would be through energy expenditure, ideally measured through marked body fluid, or body calorimetry, considered as gold-standard. Nevertheless, these methods are prohibitive due to their high costs. A more feasible possibility, for countries such as Brazil, would be to assess the heart rate associated to body movements [44]. This method was not assessed, and, when compared to the method of the investigation, the other one is more precise [44].

A methodological decision may have contributed to decrease the power of detecting the association between sedentarism and MS in women, in relation to the adoption of the criteria of the International Diabetes Federation [33], preconizing the use of cut-off points of abdominal waist, adequate to the studied population. In the present study the wait measurement considered for women was greater or equal to $84 \mathrm{~cm}$, below the measurement preconized by ATP 111 [14], which was used in all the other studies mentioned above. The new definition may increase the sensitivity for the MS criteria, on one hand, and decrease the specificity, on the other hand, according to the criteria used, people included who would have been excluded if the ATPIII criteria had been used. Hopefully new national studies, with the use of the IDF criteria, may clarify the direction in which the relation between sedentarism and MS in the Brazilian is presented.

\section{References}

1. Kannel WB, Belanger AD, Agostinho R, Israel I (1986) Physical activity and physical demand on the job and risk of cardiovascular disease and death The Framingham Study. Am Heart J 112: 820-825. Link: http://bit.ly/2ZfCJke

2. Thune I, Njolstad I, Lochen ML, Førde OH (1998) Physical activity improves the metabolic risk profile in men and women in the Tromso Study. Arch Intern Med 158: 1633-1640. Link: http://bit.ly/2HdByaO

3. Gregg EW, Cauley JA, Stone K, Thompson TJ, Bauer DC, et al. (2003) Relationship of changes in physical activity and mortality among older women. JAMA 289: 2379-2386. Link: http://bit.ly/2HgcAYr
4. Blair SN, Kohl HW, Gordon NF, Paffenbarger RS (1992) How much physica activity is good for health? Annu Rev public health 13: 99-126. Link: http://bit.ly/2z8GSYF

5. Thompson PD, Bucher D, Pina IL, Balady GJ, Williams MA, et al. (2003) Exercise and physical activity in the prevention and treatment of atherosclerotic cardiovascular disease. Circulation 24: 3109-3116. Link: http://bit.ly/33JIA1R

6. Helmrich SP, Ragland DR, Leung RW, Paffenbarger RS (1991) Physical activity and reduced occurrence of non-insulin-dependent diabetes mellitus. N Engl J Med 325: 147-152. Link: http://bit.ly/2P3AVHm

7. Bray GA (1995) The syndromes of obesity: an endocrine approach. In: DeGroot LJ. Besser M. Burger HB et al. (ed) Endocrinology. Philadelphia: WB Saunders.

8. Lee CD, Blair SN, Jackson AS (1999) Cardiorespiratory fitness, body composition, and all cause and cardiovascular disease mortality in men. Am J Clin Nutr 69: 373-380. Link: http://bit.ly/20ZPhs6

9. Stevens J, Cai J, Evenson KR, Thomas R (2002) Fitness and fatness as predictors of mortality from all causes and from cardiovascular disease in men and women in the lipids research clinics study. Am J Epidemiol 156 832-841. Link: http://bit.ly/2L0jm5Q

10. Wei M, Kampert JB, Barlow CE, Nichaman MZ, Gibbons LW, et al. (1999) Relationship between low cardiorespiratory fitness and mortality in normal-weight, overweight, and obese men. JAMA 282: 1547-1553. Link: http://bit.ly/2NISC2t

11. Diaz VA, Player MS, Mainous AG, Carek PJ, Geesey ME (2006) Player MS. Mainous III AG. et al. Competing impact of excess weight versus cardiorespiratory fitness on cardiovascular risk. Am J Cardiol 98: 1468-1471. Link: http://bit.ly/2HcllCK

12. Lidfeldt J, Nyberg P, Nerbrand C, Samsioe G (2003) Socio-demographic and psychosocial factors are associated with features of the metabolic syndrome. The Women's Health in the Lund Area (WHILA) study. Diabetes Obes Metab 5: 106-112. Link: http://bit.ly/33CcTpY

13. Dietz WH (1996) The role of lifestyle in health: the epidemiology and consequences of inactivity. Proc Nutr Soc 55: 829-840. Link: http://bit.ly/2Hh3DOG

14. Third repof the National Cholesterol Education program (NCEP) (2002) Expert panel on detection, evaluation, and treatment of high blood cholesterol in adults. (Adults Treatment Panel III). Final report. Circulation 106: 3143-3421.

15. Grundy SM, Cleeman JI, Daniels SR, Donato KA, Eckel RH, et al. (2005) Diagnosis and management of the Metabolic Syndrome. An American Heart Association/ National Heart, Lung, and Blood Institute Scientific Statement. Circulation 112: 2735-2752. Link: http://bit.ly/2Z1 NabK

16. Whaley MH, Kampert JB, Kohl HW, Blair SN (1998) Physical fitness and clustering of risk factors associated with the metabolic syndrome. Med Sci Sports Exerc 7: 287-293. Link: http://bit.ly/2MmsPax

17. Irwin ML, Ainsworth BE, Mayer-Davis EJ, Addy CL, Pate RR, et al. (2002) Physical activity and metabolic syndrome in a Tri-ethnic sample of women. Obes Resea 10: 1030-1037. Link: http://bit.ly/2TLtjaZ

18. Farrel SW, Cheng YJ, Blair SN (2004) Prevalence of the metabolic syndrome across cardiorespiratory fitness levels in women. Obes Res 12: 824-830. Link: http://bit.ly/2Zb64MF

19. Finley CE, LaMonte J, Waslien Cl, Barlow CE, Blair SN, et al. (2006) Cardiorespiratory fitness, macronutrient intake, and the metabolic syndrome: The Aerobics Centre Longitudinal Study. J Am Diet Assoc 106: 673-679. Link: http://bit.ly/2HfQwgv

20. Zhu S, St-Onge MP, Heshka S, Heymsfield SB (2004) Lifestyle behaviors associated with lower risk of having metabolic syndrome. Metabolism 11 1503-1511. Link: http://bit.ly/2TOKp8a 
21. Laaksonen DE, Lakka HM, Niskanen LK, Rauramaa R, et al. (2002) Low level of leisure-time physical activity and cardiorespiratory fitness predict development of the metabolic syndrome. Diabetes Care 25: 1612-1618. Link: http://bit.ly/2Z34FZu

22. Katzmarkyk PT, Leon AS, Wilmore JH, Skinner JS, Rao DC, et al. (2003) Targeting the metabolic syndrome with exercise: evidence from the HERITAGE family study. Med Sci Sports Exerc 6: 1703-1709. Link: http://bit.ly/2P0p3FP

23. Balkau B, Vieron E, Vernay M, Born C, Arondel D, et al. (2006) The impact of 3-year changes in lifestyle habits on metabolic syndrome parameters: the D.E.S.I.R. study. Eur J Cardiovasc Prev Rehabil 13: 334-340. Link: http://bit.ly/2za7lzv

24. Ford ES, Harold WK, Mokdad AH, Ajani UA (2005) Sedentary behavior, physical Activity, and the metabolic syndrome among U.S. adults. Obes Res 13: 608-614. Link: http://bit.ly/2z7ZNmr

25. Bertrais S, Beyeme-Ondoua JP, Czernichow S, Galan P, et al. (2005) Sedentary behavior, physical Activity, and metabolic syndrome in middle-aged French subjects. Obes Res 13: 936-944. Link: http://bit.ly/2TJrRGd

26. Hallal PC, Vistora CG, Wells JC, Lima RC (2003) Physical activity: Prevalence and associated variables in Brazilian Adults. Med Sci Sports Exerc 35: 1894 1900. Link: http://bit.ly/2Zic96g

27. Monteiro CA, Wolney LC, Matsudo SM, Matsudo VR, Bonseñor VR (2003) Epidemiologia descritiva de la actividade física em horas libres en el Brasil, 1996-1997. Rev Panam Salud Publica 14: 246-254. Link: http://bit.ly/2HdpbM4

28. Oehlschlaeger MHK, Pinheiro RT, Horta B, Gelatti C, San'Tana P (2004) Prevalência e fatores associados ao sedentarismo em adolescentes de área urbana. Revista. Saúde Publica 38: 157-163. Link: http://bit.ly/2KFPpJ2

29. Pitanga A, Lessa I (2005) Prevalência e fatores associados ao sedentarismo no lazer em adultos Cad. Saúde Pública 21: 109-118. Link: http://bit.ly/2ZdOdVx

30. Teixeira MG, Barreto ML, Costa Mda C, Strina A, Martins D, et al. (2002) Sentinel areas: a monitoring strategy in public health. Cad. Saúde Pública 18 : 1189-1195. Link: http://bit.ly/33LLe5W

31. O'Brien E ,Mee F, Atkins N, Thomas M (1996) Evaluation of three devices for self-measurement of blood pressure according to the revised British Hypertension Society Protocol: The Omron HEM-705CP, Philips HP5332,and Nissi DS-175. Blood Press Monit 1: 55-61. Link: http://bit.ly/2P2nPdq
32. Myers GL, Cooper GR, Winn CL, Smith SJ (1989) The Centers for Disease ControlNational Heart Lung and Blood Institutes Lipid Standardization program. An approach to accurate and precise lipid measurements. Clin Lab Med 9: 105-135. Link: http://bit.ly/33IIU0T

33. International Diabetes Federation (2006) World definition of the metabolic syndrome. Link: http://bit.ly/33Msu6n

34. Barbosa PJB, Lessa I, Almeida Filho N, Magalhães LBNC, et al. (2006) Critério de obesidade central em população brasileira: Impacto sobre a síndrome metabólica. Arq Bras Cardiol 87: 407-414. Link: http://bit.ly/30etqOY

35. Lorvidhaya P, Stephen Huang SK (2003) Sudden cardiac death in athletes. Cardiology 100: 186-195. Link: http://bit.ly/2Zem8tc

36. Rothman Kenneth J, Greenland S (1998) Cross-Sectional Study. In: Modern Epidemiology. Second edition. New York: Lippicot Wiliam \& Wilkins.

37. Kirkhood BR (1992) Essentials of Medical Statistics. New York: Blackwell Scientific Publications. Link: http://bit.ly/2KJIYoC

38. Almeida Filho N, Lessa I, Magalhães L, Araújo MJ, Aquino E, et al. (2004) Alcohol drinking patterns by gender, ethnicity, and social class in Bahia, Brazil. Rev. Saúde Publ 38: 45-54. Link: http://bit.ly/2KScSWA

39. Lakka TA, Laaksonen DE, Lakka HM, Männikkö N, Niskanen LK, et al. (2003) Sedentary lifestyle, poor cardiorespiratory fitness, and the metabolic syndrome. Med Sci Sports Exerc 35: 1279-1286. Link: http://bit.ly/2Zebfr4

40. Carrol S, Cook CB, Butterly RJ (2000) Metabolic clustering, physical activity and fitness in nonsmoking, middle-aged men. Med Sci Sports Exerc 21: 20792086. Link: http://bit.ly/33C7TB

41. Kullo IJ, Henrud DD, Allison TG (2002) Relation of low cardiorespiratory fitness to the metabolic syndrome in middle-aged men. Am J Cardiol 90: 795797. Link: http://bit.ly/33LJR7i

42. Wareham NJ (2001) Commentary: Measuring physical activity in SubSaharan Africa. Inter J Epidemiol 30: 1369-1370. Link: http://bit.ly/2Zf7hhW

43. Rennie KL, McCarthy N, Yazdgadi N (2003) Association of metabolic syndrome with both vigorous and moderate physical activity. Inter $\mathrm{J}$ of Epidemiol 32: 600-606. Link: http://bit.ly/2z4oH6u

44. Sobngwi E, Mbanya JCN, Unwin NC (2001) Development and validation of a questionnaire for the assessment of physical activity in epidemiological studies in Sub-Sahara Africa. Inter J Epidemiol 30: 1361-1368. Link: http://bit.ly/2Z2VE2A

\section{Discover a bigger Impact and Visibility of your article publication with} Peertechz Publications

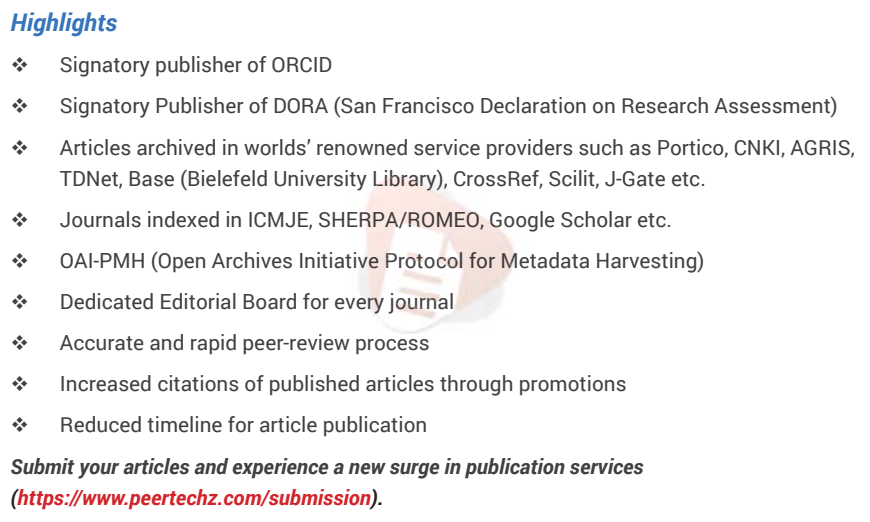

Peertechz journals wishes everlasting success in your every endeavours.

Copyright: @ 2019 Magalhães LC, et al. This is an open-access article distributed under the terms of the Creative Commons Attribution License, which permits unrestricted use, distribution, and reproduction in any medium, provided the original author and source are credited. 